\title{
Perception of University Teachers Regarding the Effects of Discussion Method on Students' Achievement
}

\author{
${ }^{a}$ Zahida Aziz Sial, ${ }^{\mathrm{b}}$ Rabia Kausar, ${ }^{\mathrm{c}}$ Hina Kanwal \\ ${ }^{a}$ Assistant Professor, Department of Education, Bahauddin Zakariya University, Multan, Pakistan \\ Email: zahidaaziz@bzu.edu.pk \\ ${ }^{\mathrm{b}}$ Visiting lecturer, Department of Education, Bahauddin Zakariya University, Multan, Pakistan \\ ${ }^{c}$ MPhil scholar, Department of Education, Bahauddin Zakariya University, Multan, Pakistan
}

\begin{tabular}{|c|c|}
\hline ARTICLE DETAILS & ABSTRACT \\
\hline $\begin{array}{l}\text { History: } \\
\text { Accepted } 26 \text { August } 2021 \\
\text { Available Online September } 2021\end{array}$ & $\begin{array}{l}\text { The main objective of this paper used to observe the perceptiveness of } \\
\text { university teachers regarding the effects of the discussion method on } \\
\text { students' success. This research paper was based on quantitative } \\
\text { research method. A questionnaire, made up of twenty seven statements, }\end{array}$ \\
\hline $\begin{array}{l}\text { Keywords: } \\
\text { Perception, University Teachers, } \\
\text { Students' Achievement }\end{array}$ & $\begin{array}{l}\text { was prepared using a five-point Likert scale with narrow answers } \\
\text { (Strongly disagree, Disagree, Undecided, Agree and (Strongly agree). } \\
\text { Collected data was processed manually in the primary phase through a } \\
\text { gender and academic sorting and after that the data feed was done in MS }\end{array}$ \\
\hline $\begin{array}{l}\text { JEL Classification: } \\
I 21, P_{3} 6\end{array}$ & $\begin{array}{l}\text { Excel by data coding. . After that the researcher carried out statistical } \\
\text { calculations using Microsoft Excel in addition to the statistical package } \\
\text { for social science (SPSS version, 17). Researcher worked out the }\end{array}$ \\
\hline DOI: $10.47067 /$ real.v4i3.189 & $\begin{array}{l}\text { frequency of the data. The results of this study showed that most } \\
\text { teachers agreed that teachers can make education more effective through } \\
\text { questioning. The method of discussion assists students in developing } \\
\text { and expressing themselves. It turned into additionally discovered that } \\
\text { tendency of instructors in the direction of the consequences of dialogue } \\
\text { strategies have been exceptionally adaptive. Finally, the researcher } \\
\text { additionally made a few hints primarily based totally on study and for } \\
\text { prospect researchers. }\end{array}$ \\
\hline
\end{tabular}

(C) 2021 The authors. Published by SPCRD Global Publishing. This is an open access article under the Creative Commons AttributionNonCommercial 4.0

Corresponding author's email address: zahidaaziz@bzu.edu.pk

\section{Introduction}

Teaching may be outline as a communiqué between instructor and the learners as a long way its related to impart of the knowledge to the learners, to wrap nearly each and every characteristic of training which the college pupils are anticipated study from a teacher and which the teacher train them the usage of different educating method, A.V aids existing to teach which consists of motivation, encouragement and personality building of the students. Khnfr (2005) said teaching techniques that focus on the pupils act and mission performance as a 
substitute than simply attainment of particulars; chances to have discourse between pupil and teacher as an important factor; chances to seek two-way group discussion; also it is an academic skill of learning in itself. In a casual learning process, a fantastic trainer generally makes use of different methods at a time. For example, a demonstration is usually accompanied way of a thorough explanation, which is mainly a lecture. Discussion can take place in a diversity of contexts and disciplines throughout the university, from seminars to labs to lectures. Engaging pupils in dialogue deepens their learning and motivation by propelling them to develop their very own perspectives and listen their own voices. Discussion techniques are diversity of debate for unlimited, mutual swap of thoughts between trainer and learners for the cause of enhancing learner's thoughts, knowledge, and trouble resolving, understanding or legendary admiration. This strategy may help in engaging large classes in group discussion and each student can participate respectively. In other methods, only a few students can participate or respond during the lecture whereas in discussion method even shy students participate. In this respect, the dominant students of the class may have to give chance to listen to others too. This method is time consuming but this time is worth consuming because each and every student has to participate and given enough time to speak up about topic. Discussion method helps in affective activity by the pupils under teacher's observation. In order to take out effective results teachers and students take into account each and every perspective. "The problem that is going to discuss by the students' group, makes a relationship between issue and its observation. Thus, then after careful observation and analyzing of the issue discussion group derive out expected results." It comprises of 3 kinds of discussion frames are used by the discussion groups in order to take out desired results and learning procedures, whole group, small group and partner talk. It helps in working relationships strong enough to help each other plus working in collaboration develops and the process of learning and participation in discussion increased.

Akande (2002) include discussion among active techniques of teaching which contain learners. Discussion was perceivedexploratory speak where participants discover thoughts and feelings together; it makes really indispensable contribution to gaining knowledge of and related for students of each and every one ages. Studies on the detailed characteristics of dialogue method, i.e., questioning, hearing, and answering in a unit form (Alvey, 2006 ;Bloom, 2007). Two essential thoughts associated with inside the phrase 'discussion' first is o speak regarding something with every other individual and a group of individuals in order to change thoughts or determine something. Second is to speak about or put in writing regarding something in detail and think about distinct thoughts and opinion regarding this. Fundamentally, dialogue is going on 3 skills, i.e., quizzing, hearing, and answering Pollard (2008), Arends(2009), Eggen \& Kauchak (2011). Those can help in the process of dialogue procedures. Thus, school room discussions need teachers must have an know-how of wherever the dialogue is headed and way to acquire there Kazemi\& Hintz (2015). Once teachers have focus learners attention on a particular gaining knowledge of aim or aims, they ought to and retain students' interest on that intention all through dialogue (Kyriakides (2013) \&McKeown\& Beck (2015) Wilkinson, Murphy, \&Binici (2015). The instructor function is to organize work so that learners are able to expand their thoughts whilst retaining a thematic center of attention Goldenberg, (1992) so as to facilitate to arrange their development. Discussions, in particular, are characterized with the aid of using by instructors utilize actual and unrestricted inquiries to each ignite and preserve dialogues Kersaint (2015) \&McKeown (2009) Soter, 2008). These are queries which have different probable reaction and significantly, queries for which feasible reactions may be no longer acknowledged or anticipate Hadjioanno (2007). Teachers strike a stability among asking queries that permit for significant searching building a latest information and no going so a long way backyard of students' current understanding base that the learners don't have anything to mention Kyriakides (2013).Teachers make at the moment decision approximately whilst about invite any other query and 
while enable for wait time Wolf (2006) to supply learners a threat to reflect on consideration on what has been stated and to originates their answers. Further, while instructors steered within the use of wait time, studies have exposed a cascade effect, encouraging different actions which boost dialogue along with fewer instructors' dialogue and less low-stage queries. Kyriakides (2013) argued that the duration of break ought to rely on the form of query being asked. Though experiential research has started to report the significance of questioning for educating practice for the maximum part, small " $\mathrm{n}$ " case research, observational studies, and theoretical part help those disputations with inside the context of dialogue another purpose of queries to pass the dialogue together with Henning (2005) so queries have to be tactical Wolf (2006). Over time, and with practice engaging in tactical dialogues, learners can start to ask queries of the instructor and each other that exhibit and get deeper grasp (Applebee 2003\& Langer, 2003).

In order to make discussion method more considerable, there are three different stages, $1^{\text {st }}$ planning, $2^{\text {nd }}$ preparation and $3^{\text {rd }}$ discussion. $1^{\text {st }}$ planning: planning should be as effective as to be successful. If discussion holder wants results, it should be well-directed. It further divided into three steps: preparation, discussion and evaluation. ${ }^{\text {nd }}$ preparation stage: which involves teacher's introduction to the topic and explain certain steps in order to make it more clear to the students. Teacher should hold important points more elaborately and discussed these very points to the students. $3^{\text {rd }}$ discussion stage: Teacher should conduct the discussion in a manner that could be easily got by the students. This kind of discussion should be face to face or counter talk. Students should exchange enough informative ideas with other students under teacher's supervision. Everyone in the setting should participate in the discussion and should give one's point of view. This method requires queries and comments in order to make point of view clearer. In this manner problem could be solved by the participants. As more minds have a lot of ideas regarding issue. Teacher should supervise the discussion in a manner that comments and ideas should not be got wiled and hatful. Teacher should discourage agitative comments and make the environment of the setting relaxed. Teacher ought to see that discussion should not be heated rather it should be very creative, impartial and supportive in the respect of problem solving. In evaluation stage: certain results are needed to be particularized. This has to be under observation that these results are safe to derive out through discussion method. The results like increase of information, intolerance is eliminated and interest in removing problem has been increased (yadav, 2003).

There should be some general guidelines which are to be followed both by the teachers and students: key points of the discussion should be gripped by the participants so that the issue should be resolved through the discussion. This method includes topic controlled and strengthen communication among the participants. Students should be satisfied and contented with the discussion and problem solution. In this way those students who feel shy or not good at expressing themselves sees a good opportunity to speak up. Establish some guidelines and parameters should be shared by the teacher but it may somehow become rigid and students may consider it stoppage of their freedom. Take note of the students' interest and engage them into the discussion positively. Students should be provided enough of the facilities to prepare discussion material. Give them a variety of learning material like, watching, listening, and reading etc. because no one wants to be humiliated and speaks about in front of others. Teachers should involve students in articulating healthy point of views on healthy topics. But if there arise some disagree argument teacher should guide them how to handle it and defend it. When the discussion gets on fire teacher should play a cool role and keep the discussion going on in better way. This method includes people sharing ideas, thoughts, attitudes and experiences. Discussion method involves two-way communication process. Teacher performs a kind of passive participant. All the discussions have some silence members so it's being expected from the teacher to make them talk 
enthusiastically. Teacher should contribute positively and make the young think productively, so they should be more confident in order to solve their respective problems (Rae Mart Navarro, 2013).

Jane B axter (2010) suggested an order to be followed by the students: teacher should formulate the start of the discussion so clear that students should participate in conversation deliberately (this should be included in outline of the course or be communicated verbally). Before starting a discussion teachers should be sure to write the objective where everyone can see it. It is the duty of the teacher to keep on the topic. Teacher should include students' grade wise in the discussion. According to Bloom's taxonomy good question should be asked. Bloom's taxonomy explains three stages of learning that is; cognitive, effective and psychomotor. According to him learning level goes from simple to complex. Certain factors were derived after a focused research that how could an individual student gets into great learning. Various factors were derived out of which are following; teachers didn't have enough guidance else they only followed universal curriculum. In this way students' learning, critical thinking and information develops under teachers' observation and lot more to learn for them. As every human has different point of view in response of different views, this however increase in their confidence and mind activity. In this way all the participants increase their knowledge. It also involves construction of knowledge, understanding or interpretation. It is considered as the most important method of students' learning process and getting information rather simply gets it. It helps in practicing students to think and brainstorm about a topic or issue. Here teachers' role is very important as they act as a facilitator. They design the way of discussion and involves the students in it actively. If the purpose of discussion is clear in teachers' and students' mind then the result would be as per expectations. There are many activities which can be conducted by the teacher in the class room. One of them can be used by the teacher which suits her/his students the best. Teacher can support the discussion method at its best by asking questions. As quizzes make use to support active use of minds by the students. As much queries from the students make them aware of much information about the issue, declared by Kyriakides et al.'s (2013). It arises in the students a sense of curiosity. Its teachers' responsibility to set the goal of learning of the students and make them informed about the issue. Teacher should brief the students about the most important part of the discussion. Teacher should make aware of the students about correct incorrect notions which may be important but students ignore those (Kazemi \& Hintz, 2015). After having discussion and exchanging of ideas, students have enough knowledge and information about the issue that helps them in solving the problems. Involving question asking technique make students active (Cazden \& Beck, 2003; Kersaint, 2015; McKeown et al., 2009; Nystrand et al., 2003; Soter et al., 2008). The responses of these questions may add to the issue solving material ( Hadjioannou, 2007). It is the important role of the teacher who persist the striking responses and keep the important point carry on by the participants said (Cazden \& Beck, 2003; Kyriakides et al., 2013). It is the role of teacher to keep students on result carrying route and students more curious about the topic and asking questions. (Cazden \& Beck, 2003; Wolf et al., 2006). In this way students think of possible responses of their questions. Additionally, teacher can pick up any of the groups' responses and he/she can tell them in advance about his/her plan so everyone in the group should play with responsibility (Russ, Sherin, \& Sherin, 2016). Kyriakides et al., (2013). Benefits: this method is excellent strategy for effective learning of the learners. It creates an ability to defend positions, consider others point of view. With the help of this method learner can explore a lot of techniques rather than just reading of it. Through discussion a lot more can be explore. By driving deeper through their questions and comments, learner engage at a level that helps ensure they fully understand the topic which is going to be discussed while discussion. Discussion promotes active participation of the participants in the discussion. Emphasize is on the learning not on the teaching. As far as this method aims at pupilactivity in the form of discussion rather than getting indulge into lecture method and simply teaching them with dry and dump techniques. This method is more effective as it involves in everybody's 
participation. It supports students' thinking and learning and gives access to the students' understanding. It also motivates students to work and think about the issue resolving techniques deliberately. It also stimulates critical thinking in students. It enhances students' expressions. It emphasizes on students' learning. As group discussions are helpful in resolving issues rapidly. With the help of this method talkative students may engage in a healthy activity. This also implies on noisy classroom. It enhances some of the students' leadership quality. It develops study habits. It increases problem solving ability. Creativity of the students could be judged best through this method. Motivation and confidence develop through this method. Some of the participants have a lot of knowledge which benefits those who haven't enough of the topic. It stimulates the ideas sharing habit. It is also useful for the effective understanding of the issue (Wiley \& Sons, 2005).

"Perception of university teachers regarding the effects of Discussion method on student's achievement" this issue is truly stated.

The purpose of this research was:

1. Locate out the perception of university teachers regarding the effects of discussion method on student's achievement.

2. To compare responses of male and female University teacher's regarding the effects of discussion method on student's achievement.

Research Questions of this study are:

1. What university teachers perceived regarding the effects of discussion method on student's achievement?

2. What is the dissimilarity among the responses of male and female teacher's of ( Bahauddin Zakariya University and University of Education )?

\section{Research Methodology}

The present research was aimed at perception of University teacher's regarding the effects of Discussion method on student's achievement. Research methodology, processes adopted for the existing research have been as:

\subsection{Population}

Teacher's 600 (male \& female) of Bahauddin Zkariya university Multan and all teachers 43(male and female) of University of Education Multan working in the year 2017 were its population.

\subsection{Sample}

Sample was chosen in two phases. Firstly, faculties were chosen then departments chosen and at last, 35 male and 56 female teachers of selected faculties of both universities, BahuddinZakriaya University and University of Education Multan were selected through using convenient sampling technique.

\subsection{Statistical analysis}

Data attained by using questionnaire had been entered in Excel sheet and SPSS (Version 17) tabularized and introduced in the structure of tables to attain positive conclusions. The researcher assign the marks to every choice as, SA(Strongly Agree), 5 A(Agree) 4, U(Undecided) 3, D(Disagree) 2, SD (Strongly Disagree) 1. The norm for acceptance or refusal of mean rating was three. 
the announcement whilst mean rating below 3 indicates rejection of the statement by the respondent. After assigning marks to every choice, total marks was calculated. To attain definite conclusions, proportion (\%), Arithmetic Mean $(\Sigma)$, Standard Deviation (SD) and Correlation (Pearson, R) and t-test were used to attain conclusion.

\section{Results}

Following results were drawn from data analysis.

\subsection{What do university teachers perceive about the effects of discussion method on students achievement?}

For this research question, mean score was computed on each statement of discussion method. The norm for acceptance or rejection of statement was 3.00.By following this norm14 statements have mean score more than 4.20 these areas ; many a various discussion method could be followed differently. It is used as proper technique in respect of some courses. It is a technique which helps in effective learning of the students. It also facilitates the students' reasoning as power thinking. This approach enables in creating a healthful rapport among the instructor and the taught. Learner-learner interactions help learners to learn, to listen, to challenge others' thinking, explain and defend their reasoning, respect others' opinions, wait their turn, and remain open-minded in the face of new evidence. Learning procedure is may be fascinating through discussion method. Discussion stress selfdetermining study by pupils. It based on students' activity of mind and thinking. It develops the manner of discussion policy. This approach educates the way to learn purposefully. Discussion technique allows instructors to discover management excellence amongst learners. Discussion method helps teachers in explaining fuzzy topics. It creates in students how to handle opposing arguments. This method helps in oral conversation among participants. Discussion method helps higher information about the topic. Discussion method may be used just for the learners who have previous knowledge regarding the topic. Discussions incorporate characteristics of learner-centered instruction, learners are at the center of learning process, teachers guide learners. Deep understanding of the topic is the goal of discussion. Social interaction is being emphasized in this method. In this method focus is on the accomplishment of the task which is the deep learning of the pupils. Goals for each course discussion are considered as unavoidable. Communication of these objectives with the learners helps to focus their thinking and motivate participation. It also helps teachers to develop such a curriculum in which learners' background knowledge have been developed, that is, the learners' have done preparations for the discussion activity. 
Table 1: Responses of teachers regarding discussion method

\begin{tabular}{|c|c|c|}
\hline Sr.No & Statements having mean score more than 4.20 & Mean Score \\
\hline 1 & Discussion approach follows a numerous of learning standards. & 4.40 \\
\hline 2 & $\begin{array}{l}\text { Discussion technique is found to work properly in case of included } \\
\text { courses. }\end{array}$ & 4.27 \\
\hline 3 & $\begin{array}{l}\text { Discussion method facilitates in encouraging the learners for } \\
\text { learning. }\end{array}$ & 4.26 \\
\hline 4 & $\begin{array}{l}\text { Discussion method facilitates to strengthen the powers of reasoning } \\
\text { in learners. }\end{array}$ & $4 \cdot 34$ \\
\hline 5 & $\begin{array}{l}\text { Discussion approach enables in creating a healthful rapport among } \\
\text { the instructor and the taught. }\end{array}$ & 4.26 \\
\hline 6 & Learning process is may be fascinating through discussion method. & 4.21 \\
\hline 7 & Discussion method stress self-determining study by the pupils. & 4.28 \\
\hline 8 & Discussion approach is activity-oriented. & 4.26 \\
\hline 9 & $\begin{array}{l}\text { Discussion method guides for the development of democratic manner } \\
\text { of thinking. }\end{array}$ & 4.38 \\
\hline 10 & Discussion approach educates the way to learn purposefully. & $4 \cdot 30$ \\
\hline 11 & $\begin{array}{l}\text { Discussion technique allows instructors to discover management } \\
\text { excellence amongst learners. }\end{array}$ & $4 \cdot 38$ \\
\hline 12 & Discussion method helps teachers in explaining fuzzy topics. & 4.29 \\
\hline 13 & Discussion method helps higher information about the topic. & 4.33 \\
\hline 14 & $\begin{array}{l}\text { Discussion method may be used just for the learners who have } \\
\text { previous knowledge regarding the topic. }\end{array}$ & 4.23 \\
\hline
\end{tabular}

3.2 What is the distinction among the feedback of female and male teachers of Bahauddin Zakariya University and University of Education?

The mean result of Bahauddin Zakariya University teachers' sample was 229.87 and University of Education teachers' mean result was 223.74. The mean result of the Bahauddin Zakariya University teachers' was higher than the mean of the University of Education teachers. The difference of means indicate the better performance of the Bahauddin Zakariya University teachers. Which indicates that their no significance between Bahauddin Zakariya University and university of Education. The significance level was (0.05).

Table 2: Gender wise comparison

\begin{tabular}{|c|c|c|c|c|c|c|c|}
\hline & Gender & $\mathrm{N}$ & Mean & Std. Deviation & t-value & Df & p-value \\
\hline $\begin{array}{llr}\text { Effects } & \text { of } & \text { Discussion } \\
\text { method } & \text { on } & \text { student's }\end{array}$ & Male & 30 & 226.37 & 19.902 & \multirow{2}{*}{-.699} & \multirow{2}{*}{84} & \multirow{2}{*}{.486} \\
\hline university teachers & Female & 56 & 229.23 & 17.102 & & & \\
\hline
\end{tabular}

Above table shows difference of responses of male and female University teachers. The mean score of male University teachers was $\mathbf{2 2 6 . 3 7}$ while the mean score of female University teachers was 
229.23. The differentiation of mean indicates the little better performance of the female University teachers. In case of t-test value, the value of $\mathrm{p}$ is .486 at (0.05) level of significance which is greater than the t-value.

\section{Conclusion}

The questionnaire was consisted on twenty seven items. The evaluation became made Statement sensible, gender sensible and University sensible evaluation became made. Each object became additionally analyzed separately. The norm for the acceptance and rejection of declaration at the part of instructors became 3.00. Out of twenty seven statements the mean score of seven statements became greater than4.50. Teachers emphasize main points at the end of the discussion. In discussion method, the instructor summarizes the content at the end of the discussion .The language of the instructor may be made appropriate to all students. In this method, the participants can gain a huge quantity of knowledge. Also this approach simply suits in whilst introducing any topic. While the suggest rating of forty three statements became greater than 4.00 while the same time as the suggest rating of four statements became much less than 4.00 which can be $3.90,3.71,3.40,3.38$. It is helpful in case of nonavailability of related teaching learning materials. In discussion method four things can be characterized best learning. Discussions are best used to explore relationship, integrate ideas and develop thinking and interpersonal skills. Good questions are key to a productive discussion as they used to probe for deeper analysis, as for clarifications or examples and explore implications. Discussion technique, the pupils have to obey the guidelines of discussion. The teacher may also no longer capable to give authentic management in the topic of discussion.

\section{References}

Khnyfr, H.( 2005) The higher education system in the world with strategy. Journal of Cultural Management. 2005; 3(9): 10

Mangal, \& S.K Mangal, (2014) Essential of educational technology, Delhi, Ashoke pubisher.

Mangle, S.K(2014) Essentials of Educational Technology” New Delhi PHI Learning.

Akande, (2002) The Theory and Practice of Professional Teaching, Lagos, Nigeria: Ekamag Publishers, pp. 86-87.

Alvey (2006) Bloom, BS (2007). Two major ideas related in the word discussion (Fourth ed.) Pearson Education, Inc, pp. 228-224.

Kauchak, D; Eggen P (2011). Introduction to Teaching, Becoming a Professional, (Fourth ed.), New Jersey: Pearson Education, Inc.

Pollard, (2008) \& Arends, (2009) \& Kauchak, D; Eggen P (2011). Introduction to Teaching, Becoming a Professional, (Fourth ed.), New Jersey: Pearson Education, Inc.

Kazemi, E., \& Hintz, A. (2015). Intentional talk: How to structure and lead productive mathematical discussions. Portland, ME: Stenhouse.

McKeown, M. G., \& Beck, I. L. (2015). Effective classroom talk is reading comprehension. In C. S. Asterhan, S. N. Clarke, \& L. B. Resnick (Eds.), Socializing intelligence through academic talk and dialogue. Washington, DC: American Educational Research Association.

McKeown, M. G., Beck, I. L., \& Blake, R. G. (2009). Rethinking reading comprehension instruction: A comparison of instruction for strategies and content approaches. Reading Research Quarterly, 44(3), 218-253.

Applebee, A. N., Langer, J. A., Nystrand, M., \& Gamoran, A. (2003). Discussion-based approaches to developing understanding: Classroom instruction and student performance in middle and high school English. American Educational Research Journal, 40(3), 685- 730.

Goldenberg, C. (1992). Instructional conversations: Promoting comprehension through discussion. The 
Reading Teacher, 46(4), 316-326.

Hadjioannou, X. (2007). Bringing the background to the foreground: What do classroom environments that support authentic discussions look like? American Educational Research Journal, 44(2), 370-399.

Kyriakides, L Christoforou, C., \& Charalambous, C. Y. (2013). What matters for student learning outcomes: A meta-analysis of studies exploring factors of effective teaching. Teaching and Teacher Education, 143. doi:10.1016/j.tate.2013.07.010

Neelam Yadave, 2003, A Hand Book of Educational Technology, New dehli. Anmol, Publications. 